\title{
Bombus Arılarında Tarlacı İşçi Arıların Entomopatojen Funguslara Maruz Kalması Kolonideki Diğer Bireyleri Nasıl Etkiler?
}

\author{
Ayhan GÖSTERIT**1, Ozan DEMİÖZER ${ }^{2}$ \\ ${ }^{1}$ Isparta Uygulamalı Bilimler Üniversitesi, Ziraat Fakültesi, Zootekni Bölümü, Isparta \\ ${ }^{2}$ Isparta Uygulamalı Bilimler Üniversitesi, Ziraat Fakültesi, Bitki Koruma Bölümü, Isparta
}

Ayhan GÖSTERIT, ORCID No:0000-0001-9686-7992, Ozan DEMIRÖZER, ORCID No:0000-0001-7240-8898

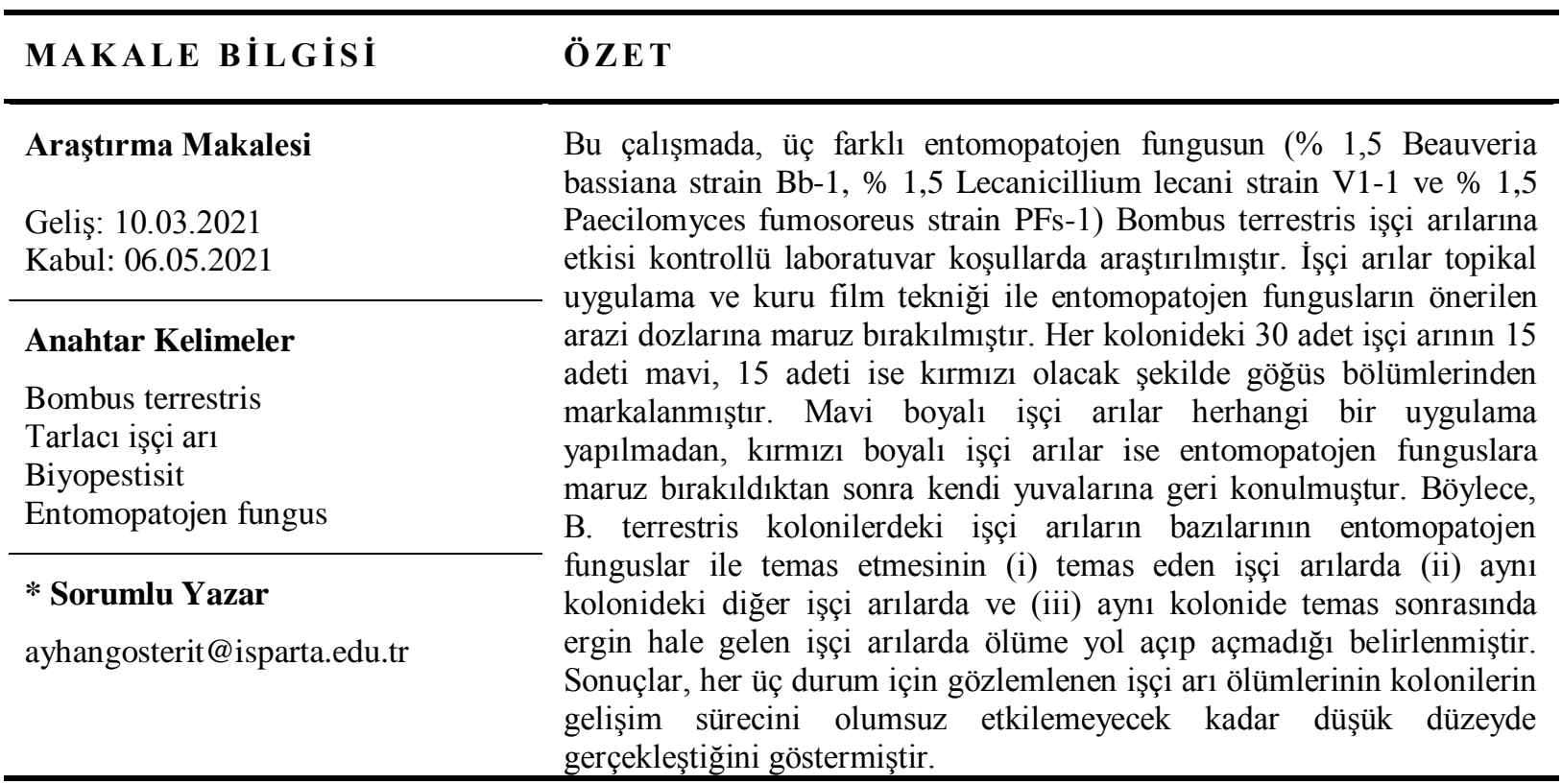

\section{How Does the Entomopatogenic Fungi Exposure of Forager Workers Affect the Other Individuals in Colony in Bumblebees?}

\section{ARTICLE INFO}

Research Article

Received : 10.03.2021

Accepted : 06.05.2021

\section{Keywords \\ Bombus terrestris \\ Forager worker \\ Biopesticide \\ Entomopathogenic fungi

\footnotetext{
* Corresponding Author

ayhangosterit@isparta.edu.tr
}

\section{A B STRA CT}

In this study, effect of three entomopathogenic fungi (\% 1.5 Beauveria bassiana strain Bb-1, \% 1.5 Lecanicillium lecani strain V1-1 and \% 1.5 Paecilomyces fumosoreus strain PFs-1) on Bombus terrestris workers was investigated under controlled laboratory conditions. Workers were exposed to recommended doses of entomopathogenic fungi by topical application and dry film method. Of the 30 workers in each colony, 15 of them were marked in blue and 15 of them were marked in red on their thorax. While the blue marked workers were put back to their own nests without any application, red marked workers were put back after entomopathogenic fungi exposure. Thus, it was investigated whether the entomopatogenic fungi exposure of some workers in $B$. terrestris colonies causes death or not in (i) in exposed workers (ii) in other workers in the same colony, and (iii) in workers that emerged after entomopathogenic fungi application in the same colony. Results showed that death values for all three cases were low level to adversely affect the colony development. 


\section{Giriş}

Dünyadaki tarımsal ürünlerin yaklaşık \% 75 'inin meyve ve tohum seti oluşturabilmesi için tozlaştırıcı böceklere ihtiyaç duyuyor olması böceklerin tozlaşma açısından önemini açıkça ortaya koymaktadır (Klein ve ark., 2006). Böcek polinasyonu bir taraftan ekosistem servisi iken diğer taraftan tarımsal üretimde bir üretim pratiği özelliğine de sahiptir. Tozlayıcı böcekler içerisinde büyük koloni oluşturması ve modern kovanlar sayesinde kolay yönetilebilmesi ve taşınabilmesi gibi sebeplerden dolayı bal arıları zirai ürünlerin üretiminde en çok tercih edilen tozlayıcı tür olsa da Nomia spp., Osmia spp., Megachile spp. ve Bombus spp. türleri de bir çok doğal ve kültüre alınmış bitkide tozlaştırıcı olarak kullanılmaktadır (Allsopp ve ark., 2008; Potts ve ark., 2010; Gösterit ve ark., 2017; Türk ve ark., 2018). Bununla birlikte günümüzde başta bal arıları olmak üzere bir çok yaban arısı türünün azalma veya yok olma tehlikesi ile karşı karşıya olduğu sıklıkla tartışılmaktadır (Gallai ve ark., 2009). Yararlandıkları çiçekli bitki bolluğunun azalması, iklim değişiklikleri, yuva yerlerini içerebilecek doğal alanların bozulması ve pestisitler başta olmak üzere tarımsal mücadele amacıyla kullanılan kimyasallara maruz kalmaları arıları tehdit eden önemli stres faktörleridir (Erkan ve Gösterit, 2012; Rhodes, 2018).

İnsektisitler başta olmak üzere pestisitlerin çoğu arılar üzerinde bireysel ve koloni düzeyinde olumsuz etkiler oluşturabilmektedir (Gill ve ark., 2012). Kültür bitkilerinin tozlaşmasında kullanılan ve karasal ekosistemin de önemli bir parçası olan bombus arıları, püskürtme uygulamalarıyla doğrudan ya da bulaşık nektar ve polenleri tüketerek dolaylı olarak pestisitlere maruz kalabilmektedir (Lamsa ve ark., 2018). Özellikle, seralarda işçi arılarda yaşanan ölümler dolaylı pestisit maruziyetinin ciddiyetini göz önüne sererken, ölmeyen bireylerde ise polen tüketimi, ovipozisyon süresi, besin arama, üreme, erkek arı üretimi ve pupadan çıkış zamanındaki anormallikler de pestisitlerin sub-lethal etkileri olarak ortaya ç1kabilmektedir (Mommaerts ve Smagghe, 2011).

Pestisitlerin bilinen olumsuz etkilerinden dolayı bitkisel üretimde hastalık, zararlı ve yabancı otların kontrolünde farklı çözüm arayışları hızlanmış ve çevre unsurlarına zararsız ya da çok az zararlı mücadele yöntem ve etmenlerin kullanımı üzerinde yoğunlaşılmıştır. Bu yöntemler içinde özellikle tarım zararlısı böceklerin bütün gelişim dönemlerine saldırabilme yeteneğine sahip olan entomopatojen fungusların kullanımı umut verici bir alternatif çözüm olarak düşünülmektedir (Poprawski ve ark., 2000; Pineda ve ark., 2008). Bitkisel üretimde zararlı kontrolünde en çok kullanılan ticari entomopatojen fungus türlerinin başında Beauveria bassiana, Metarhizium anisopliae, Isaria (Paecilomyces) fumosoroseus ve Lecanicillium (Verticillium) lecanii gelmekte olup, bu türler ülkemizin de içinde bulunduğu birçok ülkede çeşitli zararlıların mücadelesinde kullanılmaktadır (Rath, 2000; Luangsa ve ark., 2005). Günümüzde zararlı kontrolünde kullanımı yaygınlaşan entomopatojen fungus preparatları, toplam pestisit pazarının \% 1,3' ünü oluşturmaktadır (Maina ve ark., 2018). Son dönemde tarımsal üretimde hedef dışı organizmalara olumsuz etkileri nedeniyle kimyasal içerikli pestisitlere alternatif olarak sunulan entomopatojen içerikli bitki koruma ürünlerinin hedef dışı organizmalar üzerindeki etkileri, ölüme yol açıp açmadıkları ya da diğer organizmaların biyolojileri üzerinde herhangi bir olumsuz duruma yol açıp açmadıklarını ortaya çıkarmak üzere yapılan çalışmalar önem kazanmıştır. Bu çalışmada örtü altı yetiştiricilikte zararlılar ile mücadele amacıyla kullanılan entomopatojen fungusların Bombus 
terrestris işçi arıları üzerine doğrudan ve kolonideki diğer bireylere dolaylı etkileri laboratuvar koşullarında araştırılmıştır.

\section{Materyal ve Yöntem}

Araştırmanın arı materyali olarak Bombus terrestris kolonileri kullanılmıştır. Kimyasal materyal olarak ise örtü altı üretimde beyazsinek (Bemisia tabaci Gennadius, Hemiptera: Aleyrodidae) ve batı çiçek thripsi (Frankiniella occidentalis Pergande, Thysanoptera: Thripidae) zararlılarına ruhsatlı \% 1,5 Lecanicillium lecani strain V1-1, yeşil kurt (Helicoverpa armigera Hübner Lepidoptera: Noctuidae) zararlısına ruhsatlı \% 1,5 Beauveria bassiana strain Bb-1 ve iki noktalı kırmızı̈rümcek (Tetranychus urticae Koch, Acarina: Tetranchidae) zararlısına ruhsatlı olan \% 1,5 Isaria (Paecilomyces) fumosoreus strain PFs-1 olmak üzere üç farklı entomopatojen fungus içerikli preparat kullanılmıştır.

Araştırma Isparta Uygulamalı Bilimler Üniversitesi Ziraat Fakültesi, Zootekni Bölümü bünyesinde yer alan Arıcılık Araştırma ve Uygulama Laboratuvarında, kontrollü koşullarda (sıcaklık: 27-28 ${ }^{\circ} \mathrm{C}$; oransal nem: \% 50-55) yürütülmüştür. Entomopatojen funguslar tavsiye edilen arazi dozlarında $(250 \mathrm{ml} / 100 \mathrm{~L} \mathrm{su})$ bombus işçi arılarına topikal ve kuru film (kalıntı) olmak üzere iki farklı teknikle uygulanmıştır. Araştırmada her bir uygulama yönteminde 4 grup ( 3 entomopatojen fungus ve 1 kontrol) olmak üzere 8 grup oluşturulmuş ve her grupta 7 adet olmak üzere toplam 56 adet $B$. terrestris kolonisi kullanılmıştır.

Kullanılan her bir koloninin 30 adet işçi arıya sahip ve kuluçka alanı genişliği bakımından homojen olması sağlanmıştır. Topikal ve kuru film uygulama gruplarında yer alan her kolonideki işçi arıların 15 adeti mavi, 15 adeti ise kırmızı olacak şekilde ana arı boyama kalemi kullanılarak gögüs bölümlerinden markalanmıştır. Her kolonideki markalanmış ve yuvalarından alınarak bir kavanoza konulan 30 adet işçi arıya hareketsiz hale gelene kadar $\mathrm{CO}_{2}$ verilmiştir. Her bir uygulama yöntemi için hareketsiz haldeki 15 adet mavi boyalı işçi arı başka herhangi bir uygulama yapılmadan, kırmızı boyalı 15 adet işçi arı ise entomopatojen funguslara maruz bırakıldıktan sonra yuvalarına geri konulmuştur. Böylece, bütün işçi arılara $\mathrm{CO}_{2}$ verildiğinden entomopatojen fungusa maruz bırakılan ve bırakılmayan işçi arılar üzerinde karbondioksit uygulamasının etkisi eşitlenmiştir.

Topikal uygulama tekniğine göre entomopatojenlerin uygulanmasında, her bir entomopatojen fungusun tavsiye dozunda hazırlanan süspansiyonundan mikropipet yardımıyla alınan 50 mikrolitrelik $(\mu 1)$ sivı $\mathrm{CO}_{2}$ etkisi ile bayıltılan ve hareketsiz haldeki 15 adet kırmızı boyalı işçi arının her birinin thoraksının dorsal kısmına topikal olarak uygulanmıştır (Mommaerts vd., 2009). Kuru film (kalıntı) tekniği yönteminde ise her bir entomopatojen fungusun tavsiye dozunda hazırlanan süspansiyonu $13 \times 5 \times 3 \mathrm{~cm}$ ebatlarındaki boş plastik kaplara 1 atm basınçta mistleme şeklinde püskürtme yapabilen ve kompresöre bağlı özel düzenlenmiş aparatla 20 saniye süreyle $(0,5 \mathrm{ml})$ tüm kutu iç alanını kapsayacak şekilde püskürtülmüştür. Püskürtme işleminden 10 dakika sonra her entomopatojen fungus için hazırlanan koloniye ait kırmızı boyalı işçi arılar püskürtme yapılan kutulara konulmuş, bu kutularda 15 dakika bekletilerek ayılmaları beklenmiş ve spor süspansiyonu kalıntısıyla temasları sağlandıktan sonra ait oldukları yuvalara geri verilmiştir. Böylece, topikal uygulama yöntemi ile arıların ilgili entomopatojen fungusa doğrudan maruz kalmasının, kalıntı tekniğiyle ise arıların ilgili entomopatojen fungus kalıntısına maruz kalmalarının etkisi 
incelenmiştir. Her iki uygulama yönteminde ayrı ayrı oluşturulan kontrol gruplarında ise uygulama şekline göre işçi arılar üzerine veya plastik kaplara steril saf su uygulanmıştır.

Yukarıda bahsedilen uygulamalar gerçekleştirildikten sonra koloniler 4,8 ve 12 . günlerde 3 defa kontrol edilmiştir. Gözlemler sırasında kolonilerdeki ölü ve canlı işçi arı sayıları; mavi renkli, kırmızı renkli ve boyasız (uygulamadan sonra ergin hale gelecek işçi arılar) olmaları dikkate alınarak ayrı ayrı kaydedilmiştir. Elde edilen veriler SPSS (Versiyon 20.0) istatistik paket programları kullanılarak analiz edilmiştir. Meydana gelen ölüm değerleri ile ilgili veriler non-parametrik olduğundan Kruskal-Wallis testinden faydalanılmıştır. Gruplar arasındaki farklılıkların belirlenmesinde Tukey'in çoklu karşılaştırma testinden faydalanılmıştır.

\section{Bulgular ve Tartışma}

Araştırmada Bombus terrestris kolonilerdeki işçi arıların bazılarının entomopatojen funguslar ile temas etmesinin (i) temas eden işçi arılarda (ii) temas eden işçi arılar ile temas anında aynı kolonide bulunan işçi arılarda ve (iii) temas eden işçi arıların bulunduğu kolonilerde temas sonrasında ergin hale gelen işçi arılarda ölüme yol açıp açmadığı araştırılmıştır. Her gözlem gününde uygulama yapılan (kırmızı), uygulama yapılmayan (mavi) ve sonradan ergin hale gelen (boyasız) işçi arılara ait ölü birey sayıları kümülatif olarak tablolar halinde verilmiştir. Entomopatojen fungus uygulanmasından sonraki dördüncü günde her grup kendi içinde değerlendirildiğinde uygulama yapılan, uygulama yapılmayan ve sonradan ergin hale gelen işçi arılar için ölen kümülatif işçi arı sayısı bakımından önemli farklılık bulunmamıştır (Tablo 1). Ayrıca, dördüncü günde her iki uygulama yöntemindeki 4 grup kendi arasında karşılaştırıldığında işçi arı ölümü bakımından gözlemlenen farklılıklar ve her bir fungus uygulama yöntemi bakımından karşılaştırıldığında gözlemlenen farklılıklar da önemsiz bulunmuştur.

Tablo 1. Dördüncü günde ölen ișçi arı sayılarına ait kümülatif değerler (Ort. \pm St. hata)

Table 1. Cumulative values of the number of died workers on the fourth day (Mean \pm S.E)

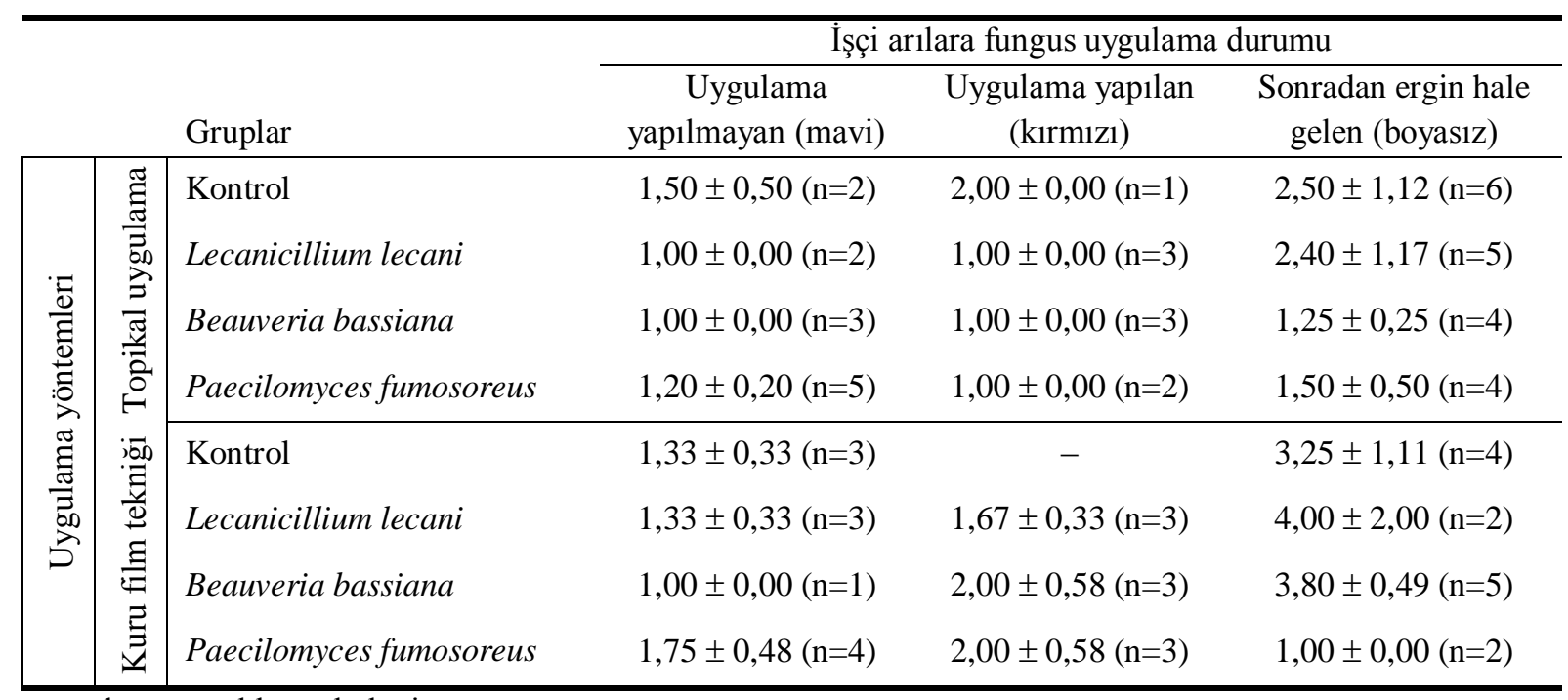

n= ölüm gerçekleşen koloni sayısı 
Uygulamadan sekiz gün sonra sadece \% 1,5 Lecanicillium lecani strain V1-1 fungus uygulamasının topikal olarak yapıldığı grupta uygulama yapılan ve sonradan ergin hale gelen işçi arıların kümülatif ölüm sayıları bakımından farklılıklar önemli $(\mathrm{P}<0,05)$, diğer gözlenen farklılıklar ise önemsiz bulunmuştur (Tablo 2).

Tablo 2. Sekizinci günde ölen işçi arı sayılarına ait kümülatif değerler (Ort. \pm St. hata)

Table 2. Cumulative values of the number of died workers on the eighth day (Mean \pm S.E)

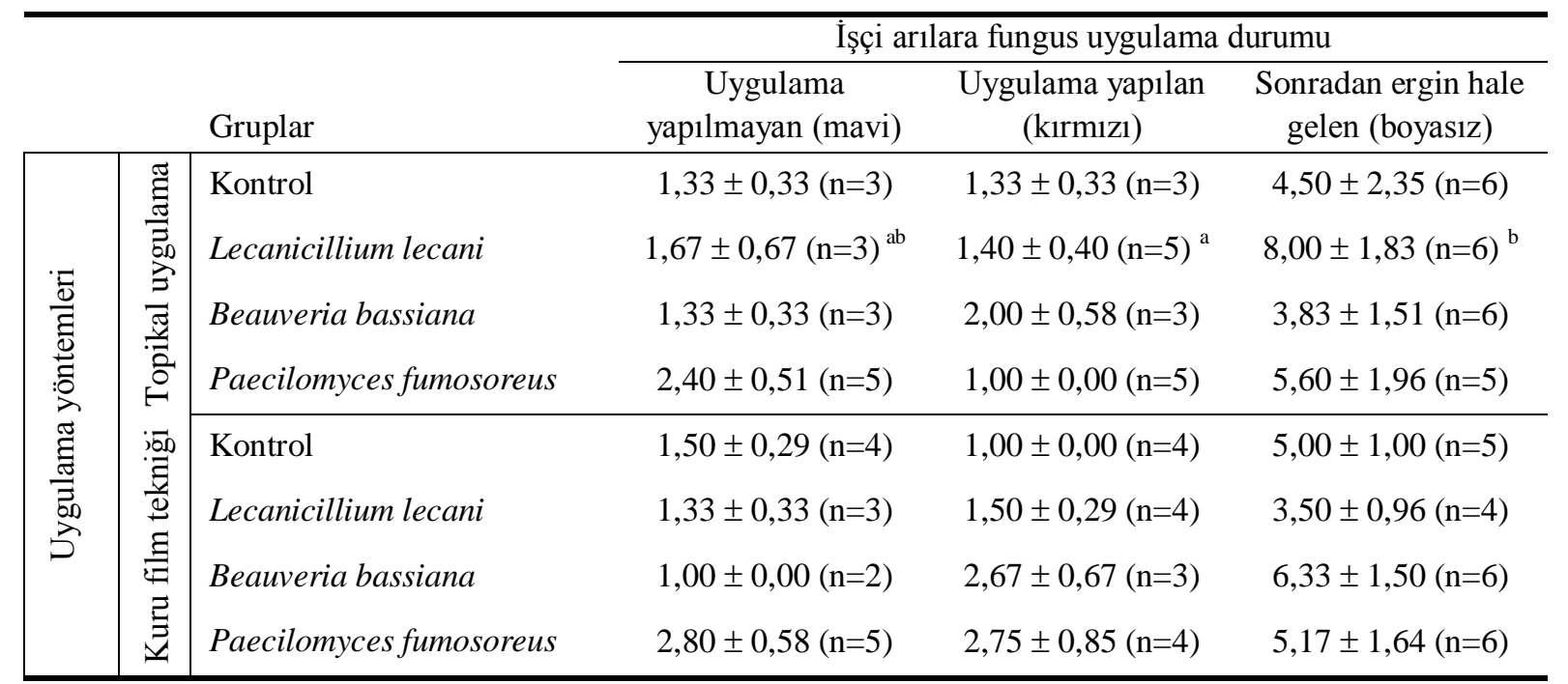

$\mathrm{n}=$ ölüm gerçekleşen koloni sayısı; a, b: Aynı satırda farklı harfleri taşıyan ortalamalar arasındaki farklılık önemlidir; $\mathrm{P}<0,05$

Çizelge 3. On ikinci günde ölen işçi arı sayılarına ait kümülatif değerler (Ort. \pm St. hata) Table 3. Cumulative values of the number of died workers on the twelfth day (Mean \pm S.E)

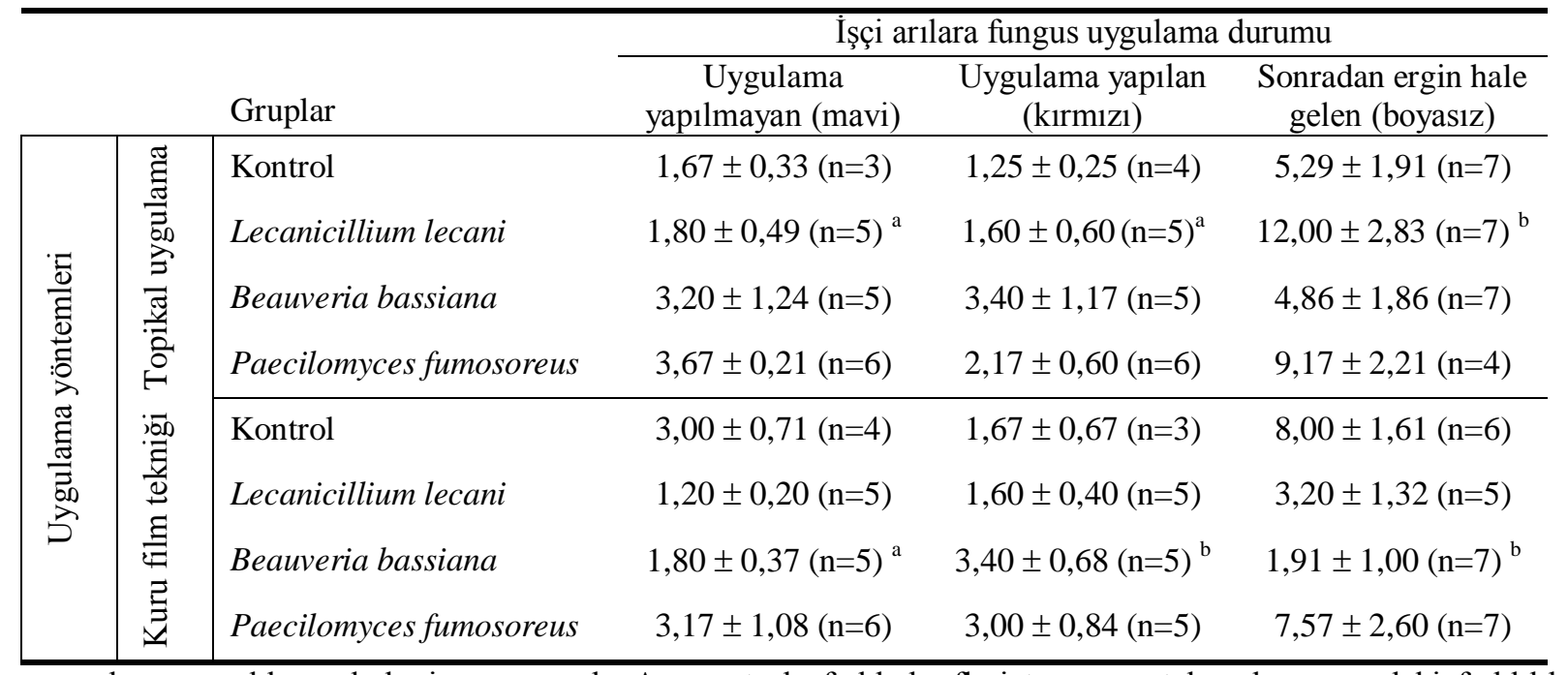

$\mathrm{n}=$ ölüm gerçekleşen koloni sayısı; a, b: Aynı satırda farklı harfleri taşıyan ortalamalar arasındaki farklılık önemlidir; $\mathrm{P}<0,05$

Araştırmada fungus uygulanmasından sonraki on ikinci güne ilişkin kümülatif ölüm değerleri Tablo 3'te verilmiştir. Sonuçlara göre \% 1,5 Lecanicillium lecani strain V1-1 uygulamasının topikal olarak yapıldığ 1 grupta sonradan ergin hale gelen işçi arıların kümülatif ölüm sayıları ile uygulama yapılmayan ve uygulama yapılan işçi arıların kümülatif ölüm sayıları bakımından farklılıklar önemli bulunmuştur $(\mathrm{P}<0,05)$. Kuru film tekniği 
uygulamasında ise \% 1,5 Beauveria bassiana strain $\mathrm{Bb}-1$ fungusuna maruz bırakılan işçi arı kolonilerinde uygulama yapılmayan işçi arıların kümülatif ölüm sayıları ile uygulama yapılan ve sonradan ergin hale gelen işçi arıların kümülatif ölüm sayıları bakımından farklılıklar önemli bulunmuştur $(\mathrm{P}<0,05)$.

Tarımsal üretimde yüksek verim elde etme isteği hastalık ve zararlılara karşı gösterilen toleransı minimum seviyelere çekmiş ve zararlı popülasyonlarını mümkün olan en düşük seviyede tutmak üzere çalışmalar gerçekleştirilmiştir (Shojaei ve ark., 2013; Nafiu ve ark., 2014). Ancak, zararlı kontrolünde sürekli pestisitlere başvuruluyor olması bu zararlıların kullanılan kimyasallara karşı direnç geliştirmesine yol açmış ve bu durum üreticilerin pestisitleri önerilenden daha yüksek dozlarda kullanmaları sonucunu doğurmuştur (Helps ve ark., 2017; Sudo ve ark., 2017). Bu kayg1 verici durum pestisitlerin arılar üzerine bilinen olumsuz etkisini her geçen gün daha da belirgin hale getirmektedir. Bu nedenle bitki koruma uygulamaları ve kullanılan ürünler gerek açık alanlardaki doğal ve kültürü yapılan bitkilerin en önemli tozlaştırıcısı olan bal arıları ve gerekse örtü altı yetiştiricilikte tozlaştırıcı vektör olarak kullanılan bombus arıları için kritik öneme sahiptir. Örtü altı yetiştiricilikte polinasyon amacıyla kullanılan bombus arılarının, zehirli tarımsal kimyasallara alternatif olarak ön plana çıkarılan entomopatojen funguslara maruz kalmaları ve bu maruziyetin etkileri göz önünde bulundurularak zararlı yönetim stratejilerinin optimize edilmesi ve dolayısıyla bombus arılarının tozlayıcı olarak performanslarını etkilemeyecek önlemlerin alınması etkili bir tozlaşma stratejisi açısından önem teşkil etmektedir. Zararlı yönetiminde sıklıkla başvurulan B. bassiana'nın, B. impatiens kullanılarak (taşıyıcı vektör) üretim alanında yayılması üzerine Shipp ve ark. (2012) tarafindan yapılan çalışmada, B. bassiana'nın bombus arısı sayesinde domates çiçeklerinde \%95 ve biber çiçeklerinde \%98 oranında yayıldığı ve fungusun $B$. impatiens üzerinde önemli oranda ölüme neden olmadığı saptanmıştır. Serada domates ve biber üretiminde zararl1 Trialeurodes vaporariorum Westwood 1856, Lygus lineolaris (Palisot de Beauvois, 1818) (Miridae) ve Myzus persicae (Sulzer) (Aphididae)'nin kontrolü amaciyla B. bassiana'nın düşük ve yüksek spor konsantrasyonlarının (düşük, 9x109 ; orta, $6.24 \times 10^{10}$; ve yüksek, $2 \times 10^{11}$ conidia $\mathrm{g}^{-1}$ ) B. impatiens'ın vektörlüğü ile zararlı böcek türlerine ulaştırılması üzerine yürütülen farklı bir çalışmada ise, düşük spor konsantrasyonlarının $B$. impatiens üzerinde olumsuz bir etkisinin saptanmadığ1, fungusun yüksek spor konsantrasyonunun ise \% 42-45 oranında ölüm meydana getirdiği belirlenmiştir (Kapongo ve ark., 2008). Zararlı kontrolünde yaygın kullanılan bir diğer entomopatojen fungus türü olan Metarhizium anisopliae (Hypocreales: Clavicipitaceae)' nin, $B$. terrestris üzerindeki etkilerinin belirlenmesi amacıyla yürütülen bir çalışmada, $10^{8}$ spor/ gram dozunda dördüncü haftada $\%$ 63 , altıncı haftada ise \%100 oranında ölüm meydana geldiği ve koloni gelişiminin olumsuz etkilendiği bildirilmiştir (Smagghe ve ark., 2013). Trichoderma harzianum ATCC20476 ve T. polysporum ATCC20475 kombinasyonlarını içeren Binab-TF-WP1 ve Binab-TF-WP-Konc ürünleri işçi arı ölümüne neden olmazken üremeyi olumsuz etkilemektedir (Mommaerts ve ark., 2008). Saf kaolin, biyofungusit Prestop-Mix (Gliocladium catenulatum + kaolin) ve biyoinsektisit olarak BotaniGard (B. bassiana)'ın B. terrestris işçi arıları üzerine lethal ve sub-lethal etkilerinin araştırıldığ 1 bir diğer çalışmada ise, kaolin ile muamele olan bombus arılarının kütiküler su kaybında artış olduğu ve hayatta kalma oranının azaldığı, BotaniGard uygulamasında ölüm oranlarının yüksek olduğu, Prestop-Mix uygulanan bireylerde ise hayatta kalma üzerine olumsuz bir etkinin olmadığı belirlenmiştir (Karise ve ark., 2016). 


\section{Sonuç}

Bombus terrestris kolonilerinde yaşam döngüsü sürecinde işçi arı ölümleri doğal olarak gerçekleşmektedir. Bazı kolonilerde beklenmeyen toplu işçi arı ölümleri ile de karşılaşılabilmektedir. Bu çalışmada da farklı uygulamalar yapılan kolonilerde işçi arı ölümleri gözlenmiştir. Ancak, gözlemlenen işçi arı ölümleri kolonilerin normal gelişim sürecini etkilemeyecek kadar düşük düzeyde gerçekleşmiştir. Araştırmada fungusların işçi arılara uygulanmasını takiben yapılan 3 ayrı gözlemde işçi arı ölümüne ilişkin elde edilen veriler incelendiğinde, sonradan ergin hale gelen (boyasız) işçi arılarda hem fungus uygulaması yapılan kırmızı boyalı hem de fungus uygulanmadan sadece maviye boyanan işçi arılara göre daha fazla ölüm olduğu belirlenmiştir. Grupların çoğunda kırmızı, mavi ve boyasız (sonradan ergin hale gelen) gruplar arasında önemli istatistiki farklılık belirlenmemesine karşın, beklenilenin aksi bir şekilde gerçekleşen bu durum dikkat çekicidir. Veriler incelendiğinde boyasız işçi arıların ölümüne ait kümülatif değerlerdeki artış kırmızı ve mavi boyalı işçi arılara göre daha hızlı olmuştur. Fungus uygulaması yapıldığı anda pupa (kapalı kuluçka dönemi) döneminde olan bu ölen boyasız işçi arıların fungusa kırmızı ve mavi renkli işçi arılar kadar temas etmediği düşünülmektedir. $\mathrm{Bu}$ nedenle kolonilerden uzaklaştırılarak boyanan ve/veya fungusa maruz bırakılan işçi arıların yaşadıkları stres sonucu yeni çıkan işçi arılara zarar vermesi veya fungusun işçi arıların kitin gelişiminin tamamlanmadığı ilk yaşlarda arılarda daha fazla olumsuz etkiye yol açması gibi ihtimaller bu beklenmedik sonuç için olası sebepler olarak değerlendirilebilir.

\section{Teşekkür}

$\mathrm{Bu}$ çalışma, 1190442 nolu proje ile Türkiye Bilimsel ve Teknolojik Araştırma Kurumu (TÜBİTAK) tarafından desteklenmiştir.

\section{Kaynaklar}

Allsopp, M. H., De Lange, W. J., Veldtman, R., 2008. Valuing insect pollination services with cost of replacement. PLOS One. 3: 3128.

Erkan, C., Gösterit, A., 2012. Bal arılarında stres. Uluslararası Türk ve Akraba Topluluklar Zootekni Kongresi, Isparta, 11-13 Eylül 2012, s. 354-362.

Gallai, N., Salles, J. M., Settele, J., Vaissiere, B., 2009. Economic valuation of the vulnerability of world agriculture confronted with pollinator decline. Ecological Economics. 68: 810-821.

Gill, R.J., Ramos-Rodriguez, O., Raine, N. E., 2012. Combined pesticide exposure severely affects individual- and colony-level traits in bees. Nature. 491: 105-109

Gösterit, A., Gürel, F., Alagöz, M., Türk, M., 2017. Determination of pollination effectiveness of different pollinators on alfalfa in Lakes Region of Turkey. 45. Apimondia Uluslararası Arıcılık Kongresi, İstanbul, 29 Eylül-4 Ekim, 2017, s. 125.

Helps, J. C., Paveley, N. D., van den Bosch, F., 2017. Identifying circumstances under which high insecticide dose increases or decreases resistance selection. Journal of Theoretical Biology. 428: 153-167. 
Kapongo, J. P., Shipp, L., Kevan, P., Broadbent, B., 2008. Optimal concentration of Beauveria bassiana vectored by bumble bees in relation to pest and bee mortality in greenhouse tomato and sweet pepper. BioControl. 53: 797-812.

Karise, R., Muljar, R., Smagghe, G., Kaart, T., Kuusik, A., Dreyersdorff, G., Williams, I. H., Mand, M., 2016. Sublethal effects of kaolin and the biopesticides Prestop-Mix and BotaniGard on metabolic rate, water loss and longevity in bumble bees (Bombus terrestris). Journal of Pest Science. 89: 171-178.

Klein, A. M., Vaissierre, B. E., Cane, J. H., Steffan-Dewenter, L., Cunningham, S. A., Kremen, C., Tscharntke, T., 2006. Importance of pollinators in changing landscapes for World crops. Proceedings of the Royal Society B. 274: 303-313.

Lamsa, J., Kuusela, E., Tuomi, J., Juntunen, S., Watts, P.C., 2018. Low dose of neonicotinoid insecticide reduces foraging motivation of bumblebees. Proceedings of the Royal Society B. 285: 20180506.

Luangsa-Ard, J. J., Hywel-Jones, N. L., Manoch, L., Samson, R. A., 2005. On the relationships of Paecilomyces sect. Isarioidea species, Mycological Research. 109(5): 581-589.

Maina, U. M., Galadima, I. B., Gambo, F. M., Zakaria, D., 2018. A review on the use of entomopathogenic fungi in the management of insect pests of field crops. Journal of Entomology and Zoology Studies. 6(1): 27-32.

Mommaerts, V., Platteau, G., Boulet, J., Sterk, G., Smagghe, G., 2008. Trichoderma-based biological control agents are compatible with the pollinator Bombus terrestris: A laboratory study. Biological Control. 46: 463-466.

Mommaerts, V., Sterk, G., Hoffmann, L., Smagghea, G., 2009. A laboratory evaluation to determine the compatibility of microbiological control agents with the pollinator Bombus terrestris. Pest Management Science. 65: 949-955.

Mommaerts, V., Smagghe, G., 2011. Entomovectoring in plant protection. Arthropod Plant Interactions. 5: 81-95.

Nafiu, B. S., Dong, H., Mustapha, S., 2014. Biological control of insect pests in West Africa: a review. International Journal of Applied Research and Technology. 3(9): 39-45.

Pineda, A., Marcos-García, M. A., 2008. Use of selected flowering plants in greenhouses to enhance aphidophagous hoverfly populations. Annales-Societe Entomologique de France. 44: 487-492.

Poprawski, T. J., Greenberg, S. M., Ciomperlik, M. A., 2000. Effect of host plant on Beauveria bassiana and Paecilomyces fumosoroseus-induced mortality of Trialeurodes vaporariorum (Homoptera: Aleyrodidae). Environmental Entomology. 29: 1048-1053.

Potts, S. G., Biesmeijer, J. C., Kremen, C., Neumann, P., Schweiger, O., Kunin, W. E., 2010. Global pollinator declines: Trends, Impact and Drivers. Trends in Ecology and Evolution. 25: 345-353.

Rath, A. C. 2000. The use of entomopathogenic fungi for control of termites. Biocontrol Science and Technology. 10: 563-581

Rhodes, C.J., 2018. Pollinator decline - an ecological calamity in the making? Science Progress. 101(2): 121-160.

Shipp, L., Kapongo, J. P., Park, H. H., Kevan, P., 2012. Effect of bee-vectored Beauveria 
bassiana on greenhouse beneficials under greenhouse cage conditions. Biological Control. 63: 135-142.

Shojaei, S. H., Hosseini, S. J. F., Mirdamadi, M., Zamanizadeh, H. R., 2013. Investigating barriers to adoption of integrated pest management technologies in Iran. Annals of Biological Research. 4(1): 39-42.

Smagghe, G., De Meyer, L., Meeus, I., Mommaerts, V., 2013. Safety and acquisition potential of Metarhizium anisopliae in entomovectoring with bumble bees, Bombus terrestris. Journal of Economic Entomology. 106(1): 277-282.

Sudo, M., Takahashi, D., Andow, D. A., Suzuki, Y., Yamanaka, T., 2017. Optimal management strategy of insecticide resistance under various insect life histories: heterogeneous timing of selection and interpatch dispersal. Evolutionary Applications. 11: 271-283.

Türk, M., Gösterit, A., Alagöz, M., Buluş, İ.Y., 2018. Korunga tohum üretiminde balarıların rolü. 6. Uluslararası Muğla Arıcılık ve Çam Balı Kongresi, Muğla, 15-19 Ekim 2018, s. 698 . 